in the neosinuses of surgical valves could have expanded our understanding of TAVR as their replacements.

Naturally, this work is also subject to some limitations. Among them, we highlight their use of a rigid substrate as opposed to a flexible one; use of a blood analog, which likely altered local hemodynamics; and use of non-subject-specific coronary flow. Finally, this work provides yet another gentle reminder that we are still learning about TAVR and should consider this uncertainty when choosing TAVR over surgical options, especially in lower-risk patients.
See Article page e105.

\section{Commentary: Just go with the flow: Transcatheter aortic valve thrombosis}

\author{
Alvise Guariento, MD, ${ }^{\mathrm{a}}$ and Nicholas $\mathrm{Oh}, \mathrm{MD}^{\mathrm{b}}$
}

As summarized by what became known as Virchow's triad, there are 3 factors that contribute to thrombosis: stasis, endothelial injury, and hypercoagulability. The first of these concepts has recently gained some attention in the world of flow dynamics, especially when applied to prosthetic valve implantation and function. ${ }^{1}$

As the indications for transcatheter aortic valve implantation (TAVI) broaden and technology improves, understanding the role of flow in aortic valves is extremely relevant, particularly how it relates to the risk of thrombosis (Figure 1). Several studies have examined thrombosis formation after TAVI through the use of retrospective clinical data and in vitro reconstruction. ${ }^{2,3}$ The main findings of these investigations correlate thrombosis with the geometry of the valve after deployment and therefore to its correct symmetrical expansion. Some data suggested that a reduced

From the a Division of Cardiovascular Surgery, The Labatt Family Heart Centre, The Hospital for Sick Children, University of Toronto, Toronto, Ontario, Canada; and ${ }^{\mathrm{b}}$ Department of Thoracic and Cardiovascular Surgery, Cleveland Clinic Foundation, Cleveland, Ohio.

Disclosures: The authors reported no conflicts of interest.

The Journal policy requires editors and reviewers to disclose conflicts of interest and to decline handling or reviewing manuscripts for which they may have a conflict of interest. The editors and reviewers of this article have no conflicts of interest.

Received for publication Nov 6, 2020; revisions received Nov 6, 2020; accepted for publication Nov 10, 2020; available ahead of print Nov 20, 2020.

Address for reprints: Alvise Guariento, MD, Division of Cardiovascular Surgery, The Hospital for Sick Children, 555 University Ave, Toronto, Ontario, Canada, M5G 1X8 (E-mail: alvise.guariento@sickkids.ca).

J Thorac Cardiovasc Surg 2022;164:e122-3

$0022-5223 / \$ 36.00$

Copyright (c) 2020 by The American Association for Thoracic Surgery

https://doi.org/10.1016/j.jtcvs.2020.11.031

\section{References}

1. Mack MJ, Leon MB, Thourani VH, Makkar R, Kodali SK, Russo M, et al. Transcatheter aortic-valve replacement with a balloon-expandable valve in low-risk patients. N Engl J Med. 2019;380:1695-705.

2. Hansson NC, Grove EL, Andersen HR, Leipsic J, Mathiassen ON, Jensen JM, et al. Transcatheter aortic valve thrombosis: incidence, predisposing factors, and clinical implications. J Am Coll Cardiol. 2016;68:2059-69.

3. Laschinger JC, Wu C, Ibrahim NG, Shuren JE. Reduced leaflet motion in bioprosthetic aortic valves-the FDA perspective. N Engl J Med. 2015;373:1996-8.

4. Trusty PM, Bhat SS, Sadri V, Salim T, Funnell E, Kamioka N, et al. The role of flow stasis in transcatheter aortic valve leaflet thrombosis. J Thorac Cardiovasc Surg. 2022;164:e105-17.

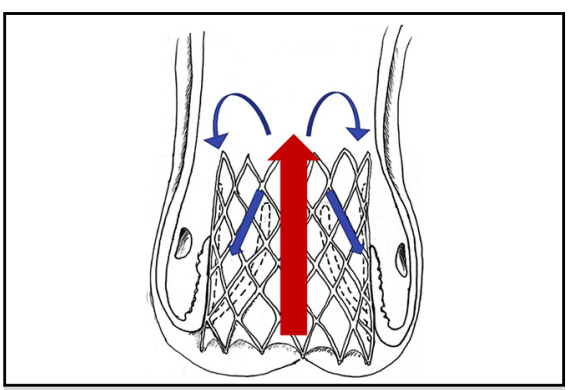

Fluid dynamics of the aortic root after transcatheter aortic valve implantation.

CENTRAL MESSAGE

More studies are needed to

investigate the pathophysiologic

factors that influence transcath-

eter aortic valve thrombosis.

flow is significantly present in the neosinus (the area between the TAVI leaflets and the stent), and this can potentially lead to thrombus formation. ${ }^{3}$

In the current issue of the Journal, Trusty and colleagues ${ }^{4}$ present an elegant study demonstrating a direct association between flow stasis in the neosinus and thrombus volume. Using in vitro simulations of reconstructed TAVI from real patients, the authors support the association of flow stagnation via washout times and neosinus thrombosis.

There are many previously investigated factors that are known to contribute to TAVI configuration, such as a patient's cardiac output, proximal aortic anatomy, implantation depth, overexpansion, or oversizing of the valve. Only some of these factors were examined in the current study, but others should be explored in follow-up studies. Nevertheless, 


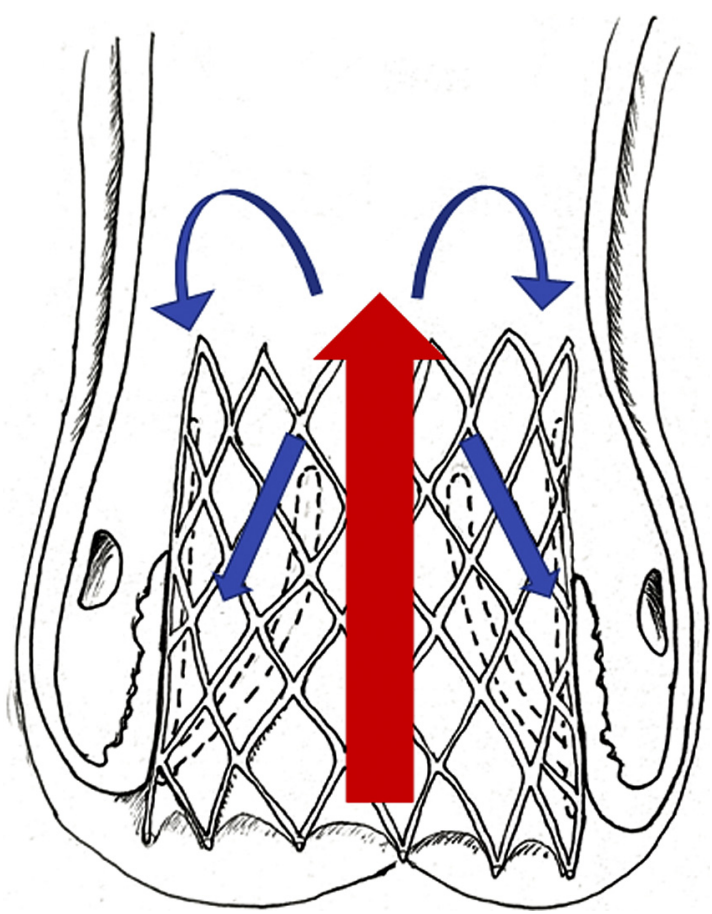

FIGURE 1. Effects of positioning of a transcatheter aortic valve on fluid dynamics of the aortic root. The fluid dynamics are often changed after TAVI when blood flows through both the neosinus (the area between the TAVI leaflets and the stent) and the anatomical (native) sinus.

the authors acknowledge that optimizing them may maximize flow in the neosinus and decrease areas of stagnation. Unfortunately, the authors did not validate their model in native or surgical prostheses, which would strengthen their results and allow the use of their model in other clinical/ research scenarios. Further imaging and computational fluid dynamics may serve as evidence in this regard. For example, using emerging 4-dimensional flow magnetic resonance imaging techniques, it would be informative to understand flow vectors in the in vivo setting and determine which valve configurations provide the best flow and consequently washout.

It is encouraging that their findings reinforce the existing literature. Increased washout time is likely a product of static or turbulent flow along the neosinus, which promotes thrombus formation. Another consideration is that TAVI valves do not replace the native aortic valve leaflets but rather are seated between them. As such, flow dynamics are often changed when blood flows through both the neosinus and anatomical (native) sinus (Figure 1). Understanding this relationship and the potential for thrombus in the anatomical sinus after TAVI implantation will be helpful in improving valve sizing and implantation depth. It may also provide greater details into the optimal alignment of the native aortic root commissures and TAVI valve commissures. One thing is clear: with studies like the one in this current issue, TAVI technology will surely improve. So, just go with the flow.

\section{References}

1. Lowe GDO. Virchow's triad revisited: abnormal flow. Pathophysiol Haemos Thromb. 2003;33:455-7.

2. Hatoum H, Moore BL, Maureira P, Dollery J, Crestanello JA, Dasi LP. Aortic sinus flow stasis likely in valve-in-valve transcatheter aortic valve implantation. $J$ Thorac Cardiovasc Surg. 2017;154:32-43.e1.

3. Midha PA, Raghav V, Sharma R, Condado JF, Okafor IU, Rami T, et al. The fluid mechanics of transcatheter heart valve leaflet thrombosis in the neo-sinus. Circulation. 2017:136:1598-609.

4. Trusty PM, Bhat SS, Sadri V, Salim MT, Funnell E, Kamioka N, et al. The role of flow stasis in transcatheter aortic valve leaflet thrombosis. $J$ Thorac Cardiovasc Surg. 2022;164:e105-17. 